\title{
The Algorithm Design and Analysis Teaching Research Based on the Practical Teaching
}

\author{
Yong LI \\ College of Computer Science and Engineering, Qujing Normal University, Qujing Yunnan 655011, \\ China \\ email:qjsfxyly@163.com
} Keywords: Algorithm design and analysis, Programming practice ability, Teaching organization
mode, Practical teaching

\begin{abstract}
Algorithm design and analysis is a core course of the computer and related professional, also is a comprehensive and practical course. Therefore, good teaching effect can not only improve students' ability on logical thinking, and also, it is beneficial for students to improve the ability of programming practice. In this paper, referencing to the teaching reform achievements on algorithm design and analysis that from other domestic key universities teacher, then, analyzed the teaching situation of algorithm design and analysis in our college. Aiming at shortcomings of the past teaching process of organization, proposed a teaching organization mode framework on algorithm design and analysis, in order to cultivate the students' ability of programming practice that electived algorithm design and analysis course. Through the implementation of the organization framework's, students can further improve and exercise their programming practice ability.
\end{abstract}

\section{Introduction}

Cultivating high-quality innovative undergraduate practice talents is our school's important training objectives, and it is our school's training goal must adhere to achieve. Programming ability is one of the most important practical ability that computer professional students must possess, is a measuring index of students' professional knowledge and is an important basis to investigate whether students have the ability to solve practical problems, also is a problem that all of professional teacher must to thinking hardly, especially teachers of programming design course need to think about carefully in daily teaching activities. Therefore, we must adhere to the cultivation of students' programming practice ability when make the teaching syllabus and the talent training scheme about computer and related professional, and it is necessary to continuous new teaching research for the algorithm design and analysis course.

\section{Teaching Present Situation Analysis}

Algorithm design and analysis is a high comprehensive, theoretical and practical professional courses, is an important specialized course of computer and related non-computer majors senior undergraduates and graduate students, rely on higher mathematics, linear algebra, discrete mathematics and combinatorial mathematics, numerical analysis, programming, data structure and so on as the pioneer, mainly aimed at some of practical application problems(such as matrix, path planning, 0-1 knapsack, etc.), to introduce how to apply dynamic programming algorithm, greedy algorithm, backtracking, branch and bound to solve the problem, and think how to design and analysis the process for students, effective and reasonable arrange the course's teaching activities can not only better to consolidate the knowledge that students have learned from previous lessons, at the same time also better to improve students' practical ability of solving concrete problem. And because of algorithm design and analysis have great significance on computer and related non-computer professional students. In recent years, many of the domestic universities teachers have researched on algorithm design and analysis teaching reform, further promote the development of algorithm design and analysis teaching. Nanjing university of aeronautics' teacher Qun DAI according to the student's 
basic situation, make the target on the content of algorithm design and analysis, make appropriate cuts on some of student hard to understand content, have a very good teaching reform effect on the limited class hour energy to study interest, cultivating students' elementary self-study [1]. Jinan university teacher Bo LIU according to the current problems existing in the course teach, have comprehensive thinking the course from teaching content, teaching methods, curriculum design, experiment and examination methods, pay attention to the central position of students in the process of teaching, and get students' consistent highly praise [2]. Shanxi normal university professor Xiaoming WANG according to algorithm design and analysis of teaching reform as the background, to explore feasible computational thinking innovation education mode and implementation framework, make the good progress in the calculation of students to cultivate students' thinking ability training[3]. In addition, Nanjing University of posts and telecommunications' teacher Lei CHEN, East China University of science and technology teacher Hong ZHENG, China University of geosciences phoenix teacher Lei PENG also make the targeted teaching reform to algorithm design and analysis of course, and also has obtained good teaching effect[4][5][6].

In our university, algorithm design and analysis course major in computer science and technology, software engineering, information and computation science three major undergraduate senior students, in the course of teaching organization, the traditional teaching mode has been used for many years, that is emphasis on theory teaching is given priority, too little or even missing algorithm programming practice, teachers usually use multimedia demonstration in theory course, teaching students about the course's teaching content with classic problems involved in algorithm design thought, teaching mathematical model, very few teachers are pay attention to how to solve problem about the classic algorithm programming practice, combined with the majority of students' original programming basis are poor in the junior stage of learning programming language, and their programming ability are insufficient, make most of students are clear to tend to problem solving ideas, construction of mathematical model, design process of the algorithm, but according to some specific practical problems, most of them are without the ability to finish in senior stage even in close to graduation. In view of this, in this paper, based on the truth of one class of algorithm design and analysis course that I'm teaching, a survey study on the targeted teaching, put forward a new teaching organization mode, used the new teaching mode to accomplish the teaching of this course, and to improve the students' programming practice ability.

\section{Programming Practice Ability Training Implementation Framework}

Combining with the teaching status quo analysis, based on the actual situation of the teaching that I served as algorithm design and analysis, have in-depth thinking in the course of algorithm design and analysis organization activities, put forward suitable for taking algorithm design and analysis course students teaching organization mode of cultivating the ability of programming practices framework, As shown in figure 1, below is the teaching organization mode framework in the algorithm design and analysis curriculum teaching, and its detail specific implementation process.

On teaching subject, mainly include senior undergraduates student and multi-level double type teaching team of algorithm design and analysis course, the position change from the relationship with teachers only simply teaching and students only learning into the relationship with paying attention to equal interactive teaching. On the choice of the teacher, we first consider the choice that teachers have rich development experience of the algorithm and program design commitment to the course teaching. In the teaching implementation process, we stressed by teachers put forward questions and help guided is given priority to, then inspire students to discuss with each other, mutual study found the algorithm design ideas to solve the problem. So, besides can better reflect teachers' guidance in the teaching, more conducive to mining each student's wisdom, embodies the equality of interaction between teachers and students. 


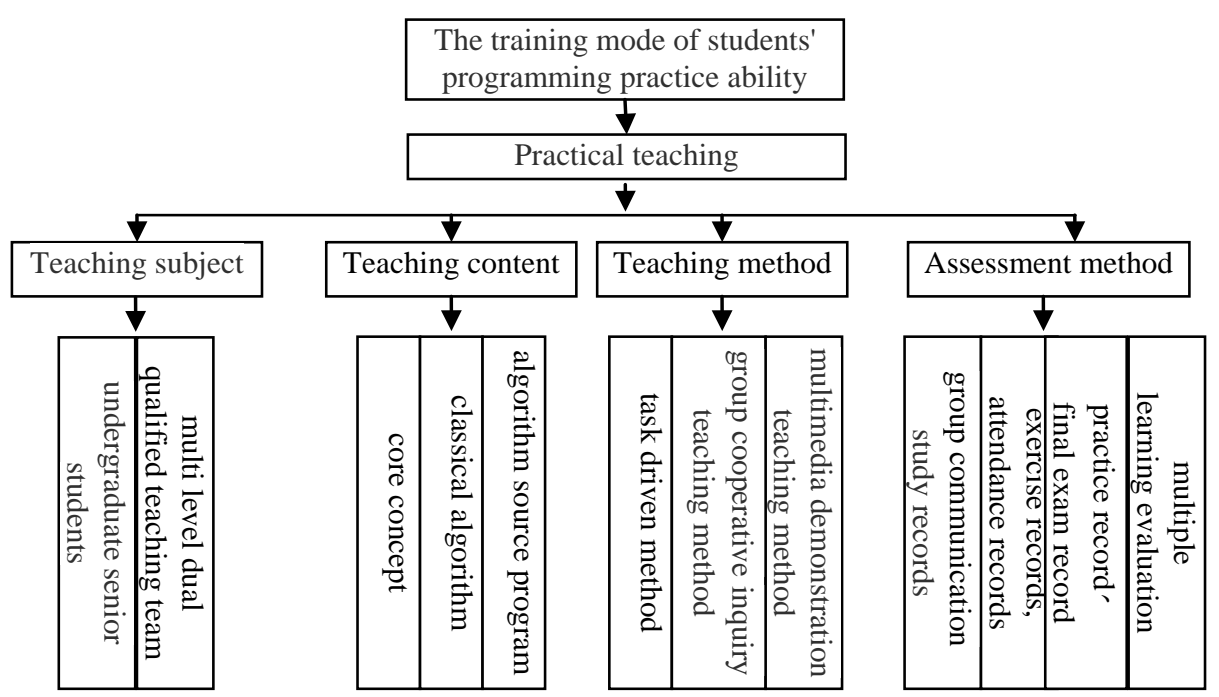

Figure.1.The teaching organization mode framework of cultivating students' programming practice ability

On teaching content, the traditional algorithm design and analysis of teaching mainly by the explain path planning, 0-1 knapsack, batch job, graph search, combinatorial optimization problem solving algorithm design is given priority to, and neglect some important concepts, and program realization of the core algorithm. Therefore, in practical teaching mode, to solving specific problem, we asked students to understand this kind of problems solving algorithm design ideas, also requires students are able to master this kind of problems, description of problems and define the key concepts and specific nature of the problems and design steps of the mathematical model and algorithm.

On teaching method, we integrated driven by tasks, group collaborative inquiry, multi-media demonstration teaching method to implement when choose teaching method, and divided students into several different study groups in class by the basis of good or bad students to match each other. In the theory class, according to the content of the class, we arranged some questions to require every team member to begin with thinking, and asked team members to communicate with each other before class discussion, then summing up the group learning experience, in order able to communicate with team members, teachers in the question discussion stage. Finally, teacher sum up the communication between teachers and students, and explain the teaching content by multimedia. Compared to the traditional spoon feeding teaching method, our teaching method is better favorable to the cultivation of students' independent thinking and problem solving ability, and it is also a great help to students' algorithm programming ability because it contains the thinking of students themselves. In the practice class, teachers should design some targeted algorithm programming tasks require students to write programs by themselves, and teachers do a good job of supervision and guid. By strengthening the training program, and deepen students' understanding of the classical algorithm application, and improved students' programming practice ability.

On assessment method, algorithm design and analysis is a strong comprehensive and practical professional elective course, the traditional curriculum $40 \%+60 \%$ assessment pattern could not good test of the students' study effect, also cannot very good to implementation the purpose of promote learning by the assessment. Therefore, in the process of practical teaching, considering accord to group discussion learning records, operation records, practice learning performance records, final assessment record, and establishing a unified learning record table for every student, the table's content and style as shown in table 1, and designing each record will be subject to 5 times, for example, at the end of the semester, student ZHANGSAN gets 5 good records in the Group discussion study records that he will get 10 points of the $10 \%$ rated, and by a deduction of $20 \%$ points, that is to say, he will only get 8 points of the 10\% rated. By analogy, other records project will evaluate every student's each item score in this way, at last, according to the situation of students' learning record to comprehensive evaluation of them course grade in final. The way of comprehensive assessment and evaluation of student achievement is not only relative fair evaluation of student performance, testing the students' study effect, more important is can be recorded by 
increasing the usual period of overall proportion of stage, shrinking the inspection record of the final grade, and strengthen learning process monitoring records at ordinary times to promote students' learning, to ensure the usual learning efficiency, truly achieved the goal of promote learning by the assessment.

Table.1. Learning records

\begin{tabular}{|l|c|}
\hline \multicolumn{1}{|c|}{ Record Project } & Score (\%) \\
\hline Group discussion study records & 10 \\
\hline Classroom speech record & 10 \\
\hline Exercise record & 10 \\
\hline Class attendance record & 10 \\
\hline Practice record & 30 \\
\hline final exam record & 30 \\
\hline
\end{tabular}

\section{Summary}

According to the need of algorithm design and analysis teaching and high quality innovative undergraduate talents training practice, on the basis of research results that algorithm design and analysis teaching reform from other domestic colleges and universities, aimed to our school's algorithm design and analysis curriculum teaching of actual situation. For our school students that have elective the course of algorithm design and analysis, we have put forward a teaching model framework for the cultivating of programming practices ability. With teaching subject, teaching content, teaching method, assessment methods four aspects to detail elaborated the teaching activities implementation process, compared with the traditional teaching mode, the new teaching mode is not only beneficial to cultivate the student self-study ability and logical thinking ability, more important is can be further improve and exercise the programming practice ability of students. But, in this paper, the study on algorithm design and analysis teaching reform is relatively single in form and content, also is not very obvious effect. Therefore, the direction of further research efforts will be based on the curriculum teaching reform, algorithm design and analysis as the foundation, to explore including other core professional courses is given priority to with programming practice ability cultivation of the curriculum group, formed as a set of mature teaching model is beneficial for cultivate students' programming practice ability.

\section{References}

[1] Qun Dai. "algorithm design and analysis of" undergraduate course teaching research [J]. Journal of computer education, 2009(9):70-72.

[2] Bo Liu. "algorithm design and analysis of" teaching study [J]. Journal of higher education of science and technology, 2007, 4:78-80.

[3] Wang Xiaoming, Junlin Lu, Sanbin Wu. Algorithm design and analysis of computational thinking training course [J]. Value engineering, 2012, 11:211-212.

[4] Lei Chen, Yiting Zhang, Jian Xu. The algorithm design and analysis teaching reform based on the innovation ability training [J]. Journal of computer education, 2010 (10), 27-29.

[5] Hong Zheng, Zhiqing Shao, Haibo Fu. A preliminary study on the Algorithm Design and Analysis Teaching Reform [J]. Journal of computer education, 2008,14:29-30.

[6] Lei Peng, Guangming Dai, Maocai Wang. The curriculum teaching methods to explore algorithm design and analysis [J]. Journal of ShanXi education, 2011, 71-72. 